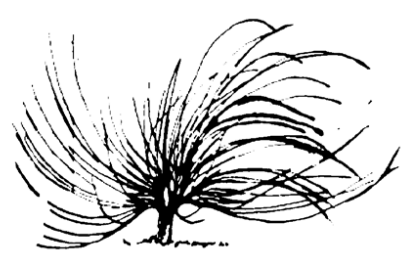

\title{
A escrita de diários de campo por alunos de letras. Da aula observada à produção do dado relevante
}

\author{
Claudia Riolf ${ }^{1}$ \\ Universidade de São Paulo \\ Brasil \\ riolfi@usp.br \\ Valdir Heitor Barzotto ${ }^{2}$ \\ Universidade de São Paulo \\ Brasil \\ barzotto@usp.br
}

\begin{abstract}
Resumo
A partir de um levantamento de dificuldades que concluintes da licenciatura em Letras mostram ao escrever, buscamos parâmetros para que, em relatos de prática, os autores descrevam uma aula, fazendo com que essa descrição funcione como dado de sua pesquisa. Por meio da análise de 1600 relatos de prática, produzidos entre 2003 e 2013, buscamos responder à pergunta: que desafios precisam ser ultrapassados pelos estudantes de letras de modo que seu texto expresse a constituição, ao longo do curso, de um olhar profissional frente: a) à aula de Lingua Portuguesa, enquanto evento de linguagem; e b) à sua própria escrita? A análise dos dados incidiu sobre três grandes temáticas: 1) como o estagiário percebe a própria tarefa de escrever diários; 2) como o estagiário registra as falas de outras pessoas; e 3) como o estagiário constrói referências temporais. Para funcionar como dado de sua pesquisa, o texto deve permitir que se leia
\end{abstract}

http://dx.doi.org/10.15359/rep.esp-20-1.1

1 Doutora em lingüística e docente da Faculdade de Educação da Universidade em São Paulo

2 Professor na Faculdade de Educação da Universidade de São Paulo. 
as especificidades do observado. $\mathrm{O}$ curso de licenciatura precisa levar o aluno a construir a capacidade de escrever bem sem perder sua condição de falante, a partir da qual ele pode se reler e se perguntar se, enquanto falante da língua materna, aceitaria seu próprio texto.

Palavras-chave: Escrita, diário de campo, formação de professores.

\begin{abstract}
We departed our research from an inventory of the difficulties faced by people who are concluding their language courses while they are writing their internship reports. We look for parameters in the internship reports in which the authors describe a classroom, making that work as research data. We tried to answer the following question: What challenges must the students face to be able to testify the construction of a professional reasoning while: a) Facing the Portuguese class as a language event? b) Reading their own text? Therefore, we analysed 1600 internship reports produced between 2003 and 2013. While analysing the data, we have investigated three themes: 1) how the trainees see their task of writing diaries; 2) how the trainees register the conversations of a third party; and 3) how the trainees construct temporal references. The undergraduate course in a Faculty of Letters should lead the student to construct the capacity of writing well. The students should develop this skill without losing their condition of speakers. Therefore, as speakers, they should be able to ask themselves if, as native speaker of their own language, they would accept their text as a good one.
\end{abstract}

Keywords: writing, field diary, teacher training 


\section{Introdução}

$\mathrm{N}$

a qualidade de pesquisadores e formadores de professores notamos que estudantes do ensino superior apresentam dificuldades básicas na escrita de textos resultantes das práticas, mais especificamente nos relatórios de estágio, embora o momento de redigi-los esteja localizado quase no fim de seu curso.

Para poder escrever bem, o estagiário precisaria enfrentar três tempos de refinamento da relação do sujeito com a linguagem (Riolfi, 2015). O primeiro consiste no trabalho motor necessário para depositar marcas gráficas em uma superfície que possibilite leitura. $\mathrm{O}$ segundo ocorre quando a pessoa, tendo essa versão grosseira da escrita em mãos, deixa que a escrita trabalhe nele, permitindo-se ser atravessado por ela. No terceiro, caso necessário ela muda sua posição e conquistar uma distância analítica com relação às próprias palavras. Nesse ponto, os autores podem trabalhar para, de modo consciente, efetuar operações textuais para construir uma ficcionalização por meio da qual o processo de construção do texto escrito fica escondido e velado para o leitor.

Lendo um conjunto dos textos resultantes das práticas de estágio (por volta de 1600 relatos), percebemos que nem sempre é possível vislumbrar a efetividade da formação prévia oferecida aos futuros professores. Para que essa formação seja mais consequente, pensamos que é necessário compreender o estágio como pesquisa na escola. Convidado a, de fato, realizar um esforço investigativo, o aluno que passa pelas práticas se vê convocado a recuperar os conteúdos aprendidos ao longo do curso, subjetivando-os ao escrever seu texto.

Levando isso em conta, nesse trabalho, apresentamos elementos de uma abordagem específica para a pesquisa que temos empreendido. Pleiteamos que a pesquisa feita ao longo das práticas esteja entre a etnografia, ou as pesquisas qualitativas, e a análise do discurso. Ou seja, não estamos mais buscando eleger uma entre as vertentes dos estudos da sala de aula ou do texto disponíveis para que sirva ao estagiário. $\mathrm{O}$ que se nota, em trabalhos feitos no interior de cada uma dessas perspectivas, é que, muito frequentemente, o pesquisador vai a campo (ou ao discurso) para efetuar recortes diretamente relacionados a uma questão de pesquisa definida previamente.

No modo como entendemos o estágio, o estagiário vai, primeiramente, produzir o texto que descreve uma aula. Para que seja possível 
descrever a aula, elementos da pesquisa qualitativa devem estar presentes, como a anotação das falas diretas e de episódios (Ludke \& André, 1986). Do mesmo modo, elementos das teorias do texto e do discurso serão necessários para abordar os dados produzidos.

$\mathrm{O}$ ato de redigir faz com que o primeiro registro seja um recorte analítico da aula inteira. A partir da percepção do que é recorrente em suas anotações, o aluno vai constituir o dado, que é fruto de uma releitura do que ele mesmo escreveu. Nesse processo, ele vai: a) reconhecer-se frente ao observado, percebendo a especificidade do foco de seu registro; e b) selecionar elementos que permitam determinar as condições para que o aluno aprenda na aula que o estagiário observou.

Para funcionar como dado de pesquisa, o texto precisa permitir que se leia as especificidades do que foi observado. Frases como os alunos conversaram durante a aula; a professora explicou o conteúdo, etc. não mostram diferenças entre a aula supostamente registrada e outra qualquer. Não comprovam nem justificam a presença do estagiário naquela aula. Para tanto, seria necessário, pelo menos, encontrar o registro do conteúdo explicado, bem como remissões ao modo como a explicação teria ocorrido.

Para contemplar os aspectos da descrição de uma aula presentes nos textos produzidos por estagiários a partir das práticas de ensino, bem como os parâmetros mínimos para a descrição de uma aula em relatos de prática, perseguimos a seguinte pergunta específica: que desafios precisam ser superados pelos estudantes de letras de modo que seu texto expresse a constituição, ao longo do curso, de um olhar profissional frente: a) à aula de Língua Portuguesa, enquanto evento de linguagem; e b) à sua própria escrita?

\section{Antecedentes e qualificação do problema}

Participando do projeto de pesquisa A escrita sobre as práticas de ensino em licenciaturas do Brasil, da Costa Rica e de Honduras: registro, análise e produção de conhecimento ${ }^{3}$, decidimos tomar como objeto específico um de seus focos, que, por sua vez, se subdivide em duas interrogações. Ele está transcrito no quadro 1, na sequência:

3 CHAMADA UNIVERSAL MCTI/CNPQ No 14/2014, coordenado por Thomas Massao Fairchild. 


\section{Quadro 1 - Recorte do projeto de pesquisa coletivo}

\begin{tabular}{|c|c|c|}
\hline \multirow[b]{2}{*}{ Foco específico } & \multicolumn{2}{|c|}{ Perguntas de pesquisa específicas } \\
\hline & $\begin{array}{l}\text { Objetivos descritivos } \\
\text { (pesquisa de campo) }\end{array}$ & $\begin{array}{l}\text { Objetivos propositivos } \\
\text { (pesquisa-ação) }\end{array}$ \\
\hline $\begin{array}{l}\text { A escrita como forma } \\
\text { de registrar uma aula }\end{array}$ & $\begin{array}{l}\text { Que aspectos da } \\
\text { descrição de uma } \\
\text { aula são exigidos e } \\
\text { efetivamente encontrados } \\
\text { nos textos produzidos por } \\
\text { licenciandos a partir das } \\
\text { práticas de ensino? }\end{array}$ & $\begin{array}{l}\text { Quais são os parâmetros } \\
\text { mínimos para que a } \\
\text { descrição de uma aula } \\
\text { funcione como dado para } \\
\text { um trabalho de pesquisa } \\
\text { do licenciando? }\end{array}$ \\
\hline
\end{tabular}

$\mathrm{O}$ foco e as perguntas transcritas no quadro 1 precisam ser considerados nesse movimento de reconhecer-se no que foi escrito e conhecer o outro na experiência registrada. Quando o estagiário vai a campo para descrever uma aula, lhe é pedido precisão na anotação das falas diretas e dos eventos. Solicita-se, também, a coleta do material distribuído ou produzido na aula.

No Brasil, alguns autores já se dedicaram à descrição da distância existente entre o que é solicitado e o produto obtido nas escritas sobre as práticas. Para explicar essas lacunas constatadas, Rezende (2010) apresenta uma hipótese que nos serve de ponto de partida:

A escrita na licenciatura representa um novo desafio para o aluno proveniente do bacharelado ao ter de fazer um exercício de interpretação do observável direto [...] dependendo, portanto, de sua própria capacidade de reunir conhecimentos provenientes de diferentes formações discursivas para entender e explicar um dado observável. Em suma, na licenciatura a escrita funciona, simultaneamente, como um elemento de formação do aluno, como um instrumento para avaliar sua competência na escrita, bem como sua capacidade de elaborar adequadamente um texto tendo em vista sua finalidade, e como um elemento de formação do professor, do profissional, desafiando-o a transpor por escrito a experiência vivida e a projetá-la no exercício da profissão. (Rezende, 2010, p. 3) 
Concordamos que, nesse momento, o aluno tem um acréscimo em seu trabalho: produzir um texto que registre a experiência vivida e, a partir do que ele mesmo registrou, encaminhar uma análise de dados que não tem anterioridade ao ato do registro inicial. $O$ dado a ser objeto de análise se configura no texto do aluno. É, portanto, inédito, nunca antes analisado.

Mesmo no caso de uma instituição tradicional e rigorosa, como é o caso do curso de Letras da USP, observações vagas ocorrem. Essas instituições "têm sido levadas a confrontar-se com subjetividades que não fazem laço facilmente com seus discursos tradicionais" (Fairchild, 2013. p.72). Essa mutação, de acordo com o autor, aponta para:

[...] a possibilidade de que os cursos de formação de professores estejam perdendo a força que seria necessária para formar os sujeitos requisitados para atuar em uma escola em que os laços discursivos encontram-se fragilizados e em que se torna cada vez mais urgente a restauração de figuras que atuem como significante-mestre, dando algo em nome de que o professor possa erigir-se em sua função. (Fairchild, 2013. p. 77)

No âmbito em que estamos discutindo, os significantes-mestre aludidos por Fairchild poderiam ser, por exemplo "rigor"; "foco"; "detalhamento"; ou seja, palavras que possam lembrar o estagiário da atitude a ser mantida, com tenacidade, durante o período de observação e registro da realidade educacional. Portanto, buscamos uma melhor compreensão da relação entre o sujeito e a língua.

Estamos propondo que os cursos de letras não sejam apenas lugares onde os alunos aprendem conteúdos a respeito das línguas, mas, fundamentalmente, lugares onde possa haver uma alteração qualitativa da relação entre o falante e sua língua materna na direção de proporcionar maior legitimação, ao escrever, daquilo que foi anteriormente conquistado na condição de falante. Nesse contexto, a linguística ganha importância na formação do professor. No capítulo intitulado $O$ papel da linguistica nos cursos de letras, Ilari (1984) afirma:

[...] parece correto esperar que o curso de Letras prepare o futuro professor para 1) avaliar as potencialidades e limitações que caracterizam a expressão e comunicação de seus alunos; 2) fixar 
para eles, com respeito a expressão e comunicação, objetivos viáveis; 3) examinar criticamente os recursos didáticos que a indústria editorial proporciona. (Ilari, 1984, p. 7)

O autor destaca objetivos da Linguística para a formação do professor: 1) desautomatizar a visão corrente dos fatos de lingua; 2) proporcionar ao futuro professor de letras a oportunidade de praticar o método de investigação próprio das ciências naturais (Ilari, 1984, p. 8).

O uso da palavra "desautomatizar" nos leva a interrogar qual seria o automático. Ilari explica que a visão automatizada dos fatos da língua seria a do falante submetido a um ensino marcado pela gramática tradicional. Fazendo uma contraposição entre a herança gramatical e as contribuições da linguística, afirma que "nosso compromisso é preparar o futuro professor para compreender a atividade de fala de seus alunos" (Ilari, 1984, p. 8).

Em nossa proposta, não só acatamos a proposição de Ilari como enfatizamos a necessidade de acolher o professor na sua condição de falante. Como "compreender a atividade de fala de seus alunos" tendo sua própria condição de falante negada? Assim compreendido e respeitado, o estagiário poderia fazer valer a capacidade que lhe permite falar como base para produzir uma escrita. ${ }^{4}$ Essa escolha levaria o estagiário a considerar os parâmetros que, em sua língua, tornam algo passível de ser partilhado de modo inteligível ao invés de delegar o papel central a uma entidade abstrata que ele imagina ser uma boa escrita.

Estando convicto da necessidade de estar atento aos parâmetros que, em sua língua materna, tornam possível o julgamento a respeito da pertinência e da relevância de um dado segmento linguístico, não ocorreria ao futuro professor, relendo-se, perguntar se ele mesmo abonaria o trecho que segue?

Dando continuidade à primeira etapa do Estágio supervisionado do curso de Licenciatura em Letras, tendo em vista a necessidade de uma experiência prática onde aplicou-se grande parte dos fundamentos aprendidos ao longo dos períodos anteriores com os princípios teóricos

4 De certo modo, a proposição de que o professor de português seja alguém que utiliza parâmetros presentes na língua, aparece também em Aiko e Barzotto (2008). Nesse trabalho, os autores analisam enunciados como 'em muitos lugares o professor só tem o livro didático para ensinar português". Para eles, equivale a dizer que o professor não é usuário da língua, que o que ele já sabe tanto quanto ao seu uso quanto à reflexão sobre ela não vale ou mesmo não lhe pertence. 
estudados, agora trabalhando em sala de aula, neste momento, aliou-se a teoria à prática, demonstrando, assim, o quanto é enriquecedor e importante esta etapa na formação acadêmica e profissional do futuro docente. (Primeiro parágrafo da apresentação de um relatório de estágio)

Chamamos a atenção para o problema da ausência da devida pontuação, de problemas de concordância e para a vagueza do parágrafo em função do uso de clichês. Parece, ainda, que o aluno entende que, para produzir seu relatório, basta reproduzir clichês, sem precisar demonstrar como as afirmações feitas por ele encontrariam expressão na prática observada. Para preencher o espaço relativo ao primeiro parágrafo do relatório, o aluno abusa dos clichês, como, por exemplo "aliou-se a teoria à prática" e "é enriquecedor e importante esta etapa na formação acadêmica e profissional do futuro docente".

Parece ainda que, seduzido pelas frases feitas, ele deixa de dar atenção a aspectos relativos não só ao uso da língua portuguesa escrita que, idealmente, seriam evidentes para àqueles que atingiram seu nível de formação, como também ao próprio uso da língua na simples condição de falante.

Ao nos depararmos com relatórios que apresentam esse tipo de problema, organizamos uma busca de elementos pertinentes à discussão que empreendemos agora, de acordo com a metodologia que será exposta no item seguinte.

\section{Metodologia da pesquisa}

O corpus de nossa pesquisa é composto de relatos de prática produzidos entre 2003 e 2013, nas disciplinas Metodologia de Ensino de Lingua Portuguesa I e II, na FE-USP. Ressalte-se que produzir e partilhar um diário de campo faz parte dos procedimentos exigidos para a aprovação.

Assim sendo, ao longo do ano, quem cursa as duas disciplinas é convocado a registrar 80 de Língua Portuguesa assistidas em escolas públicas, nos níveis fundamental e médio. Idealmente, os alunos observam fatos e precisam transformá-los em dados, nos quais se possa compreender os episódios educacionais observados que envolvem; professores e alunos.

Em média, os docentes da FEUSP ministram três disciplinas MELP ao longo de um ano letivo, com uma média de 40 alunos concluintes por turma. Assim, cada docente tem contato com cerca de 80 
diários de campo por ano. Como somos dois os autores, em cada ano letivo, somamos a quantidade de 160 diários lidos. Assim sendo, nosso corpus total, nos anos que compreendem a pesquisa apresentada nesse texto é de, aproximadamente, 1.600 diários.

Iniciamos a pesquisa fazendo um levantamento de problemas de escrita presentes nos relatos que dificultam a apreensão da realidade observada pelo estagiário. Sem a preocupação de separar os exemplos entre os adequados e os inadequados, na próxima sessão analisamos excertos: a) que apresentam, de modo exemplar, problemas de escrita; e b) trechos que exemplificam a produção de estagiários que conseguiram descrever uma aula de maneira adequada.

\section{Resultados e discussão}

Para fins de maior clareza, agruparemos os dados a serem apresentados em três grandes grupos: 1) como o estagiário percebe a própria tarefa de escrever diários; 2) como o estagiário registra as falas de outras pessoas; e 3) como o estagiário constrói referências temporais.

\section{Como o estagiário percebe a própria tarefa de escrever diários}

Uma das primeiras dificuldades que localizamos na escrita do estagiário é a de designar adequadamente / corretamente a própria tarefa de escrita do relato, isto é, estar atento às palavras que lhe foram dirigidas durante as instruções relativas ao seu estágio. Normalmente, a nomeação do produto que está sendo entregue ao professor é executada na capa do trabalho. Nela, após ter concluído a tarefa, o aluno nomeia o texto material que tem em mãos. Em alguns casos, a nomeação não corresponde ao texto, como se lê a seguir:

Resenha de observação de estágio em Língua Portuguesa

No excerto que acabamos de transcrever, o aluno não leva em conta o enunciado da tarefa que lhe foi solicitada: escrever um relatório. Não dá relevo para o significado da palavra "resenha" e, por esse motivo, a usa para substituir "relatório". Então, compromete a impressão inicial que o leitor tem de seu trabalho.

Avaliar a quantidade de exemplos ou informações necessárias para ilustrar um ponto ou retratar uma determinada situação, permitindo ao leitor fazer um julgamento da efetividade da realidade educacional observada, foi outro problema encontrado. 
$\mathrm{Na}$ aula seguinte a professora focou em elementos de gramática como crase, hífen, pontuações. Dava exemplos na lousa e pedia para os alunos a ajudarem a ir preenchendo corretamente as frases com "há", "à", "a".

Realizei a análise de comportamento, concentração e a disposição dos alunos do período vespertino e noturno para a realização da atividade proposta pelo docente.

O estagiário parece compreender que relatar "a professora focou em" já seria suficiente enquanto registro de uma aula. Embora elementos da gramática estejam indicados, não é possível apreender o suficiente da aula registrada.

A ausência de exemplos, que exigiriam uma anotação mais detalhada da aula e de seu andamento, dificulta a compreensão da mudança da atenção do aluno estagiário do conteúdo para aspectos comportamentais da turma observada. Ainda que o aluno tenha sentido a necessidade de destacar o comportamento da classe em função da condução da aula, a não explicitação do que o levou a fazê-lo dá ao relato características de equívoco, desvalorizando sua própria reflexão.

Alguns alunos, diferentemente do caso do precedente, oferecem dados bastante precisos relacionados à temporalidade da aula e aos fatos nela ocorridos. No exemplo que se segue, o autor menciona elementos simultâneos à aula com indicação espacial claras, que levam o leitor a concluir, por si, as condições adversas para a aula.

A professora Suzana entrou na sala do $9^{\circ}$ ano $\mathrm{F}$ às $13 \mathrm{~h} 00 \mathrm{~min}$. Dentro da sala somente há alguns alunos, cerca de oito alunos, que estão tranquilos, enquanto que lá fora nos corredores há uma intensa euforia. Pouco a pouco os alunos vão entrando à sala, sendo que se observa correria e brincadeira entre os alunos no corredor. As $13 \mathrm{~h} 10$ a professora fecha a porta, mas mesmo assim após cerca de 2 (dois) minutos bate à porta e a professora abre e uma aluna pede para entrar e a professora autoriza. Neste momento há 34 alunos na sala, que é bastante ampla, e eles estão bem agitados e sente-se muito calor e há somente dois ventiladores. Os alunos demoram cerca de 5 minutos para se acomodarem, sendo que neste ínterim alguns alunos de outras salas batem à 
porta pedindo cadeiras e carteiras e a professora autoriza. Finalmente, por volta das $13 \mathrm{~h} 20$ min os alunos já estão sentados, mas continuam conversando entre si e então a professora diz "boa tarde" e pede silêncio para fazer a chamada.

$\mathrm{O}$ autor foi habilidoso na inclusão de elementos que, à primeira vista, não se relacionam com o ensino de Língua Portuguesa. Lendo seu relato, percebemos que ele apresenta elementos que têm impacto no processo de ensino e de aprendizagem. Percebemos, portanto, que outro dos desafios a ser superado pelos alunos é mobilizar elementos contextuais que podem somar à compreensão do processo de ensino e aprendizagem também se revelou uma tarefa complicada para alguns dos alunos.

Como forma de superar a dificuldade que acabamos de apresentar, alguns alunos optam por uma saída sincera: explicitam os limites e as faltas da anotação, de modo a deixar o leitor informado a esse respeito.

Ela escreveu na lousa uma explicação bem básica de duas linhas com dois exemplos (infelizmente não copiei) [...].

Apresentando esse exemplo, não estamos justificando a falta de cuidado no registro da aula. Usado em excesso, o recurso da sinceridade pode não se diferenciar da anotação relapsa. Quando bem usado, o registro do limite da anotação pode revelar uma percepção, por parte do aluno, das dificuldades por ele experimentadas que não foram superadas na ocasião das anotações para posterior escrita do relatório.

A passagem das anotações feitas rapidamente in locu para a forma de relatório apresenta um desafio específico: escrever de acordo com as regras da Língua Portuguesa escrita, produzindo textos cuja forma não configure em um obstáculo para a apreensão da realidade educacional registrada. Exemplo da dificuldade de superação desse desafio pode ser encontrado no excerto a seguir.

Encontram-se descrito neste relatório as observações [...]

No excerto, encontramos problemas de concordância de gênero e número. Na norma padrão escrita da Língua Portuguesa, o sujeito da frase, "as observações", requer que o verbo "descrever" seja flexionado no feminino plural: "descritas". Outro problema está na escolha lexical do autor. 
Mesmo que conjugado corretamente, o verbo "descrever", agregado a "observações" causa ruído na leitura. Há uma inadequação semântica. Para um falante de português, o que seria descrever as observações? Em um relatório, o que se descreve são "episódios", "conteúdos", "materiais" etc.

\section{Como o estagiário registra as falas de outras pessoas}

Transcrever fidedignamente os conteúdos, com organização gráfica que permita reconhecer quais são as vozes incluídas no texto, é um dos desafios de difícil transposição, como se lê a seguir.

A professora escreve na lousa o seguinte conteúdo:

Uso do "S" ou "Z":

Escrevem-se com "S" os adjetivos com os sufixos -oso, -osa, -ense: Gosto: gostoso, gostosa, Graça: gracioso, graciosa, Teima: teimoso, teimosa, Pará: paraense. [...]

Nota-se o esforço do estagiário para transcrever os conteúdos, porém, dada a falta de capricho na organização gráfica, não se chega a entender bem o que teria sido escrito pela professora regente. Compreende-se que a temática geral é o uso do "S" ou "Z", mas não é clara a organização dos exemplos que teriam sido escolhidos pela professora regente. Falta intercalar o que foi anotado com a explicação dada pela professora. Sozinho, o leitor não consegue inferir a lógica da lição. Por exemplo, ela teria esclarecido que está partindo de substantivos para chegar nos adjetivos?

Outra fonte de dificuldade é utilizar a convenção gráfica para a inclusão de discurso relatado no texto.

Passada a introdução à uma análise e interpretação de texto, a professora iniciou os alunos sobre a perspectiva nos textos. Quais os gêneros literários que apresentam certas características diferentes dos outros. O texto jornalístico, por exemplo, que distancia o sujeito dos fatos, destacando os acontecimentos, tempo, espaço, cenário. 
O professor pergunta: "de acordo com esse enunciado, sobre o que é o texto? Por que ele é racista?".

Embora, no excerto, estejam registradas várias frases do professor, o aluno utiliza apenas duas marcas de remissão: uso do verbo perguntar e aspas em uma das frases ditas pelo professor. É preciso fazer uma observação a respeito do uso do verbo iniciar. Pode ser que o aluno tenha tentado, por meio de seu uso, indicar que a professora fala aos alunos. No entanto, apontamos dois problemas. O primeiro é que a frase não está redigida em sua forma mais usual: a professora iniciou os alunos sobre o estudo de $\mathrm{x}$. A preposição sobre associado à palavra perspectiva, provavelmente em lugar de característica, torna a frase vaga. A frase continuaria carente de referência mesmo se a troca fosse efetuada. O segundo é que, sem apresentar mais elementos, o uso de iniciar é de difícil aceitação, já que não há nada que informe se os alunos já tinham ou não tido algum conteúdo relacionado a isso.

Acrescentar observações periféricas que permitam inferir o estado da aprendizagem do aluno poderia auxiliar a solucionar o desafio que vimos de apresentar, como se lê a seguir.

Um dos alunos, Luiz, acredito, leu o texto que eles deveriam identificar os verbos. A leitura foi feita sem cadência ou ritmo.

Lendo o relato, podemos perceber o cuidado do autor ao creditar a autoria da ação registrada por ele (ler o texto). Percebemos, ainda, a tentativa de qualificar a ação de Luiz (ler sem cadência ou ritmo). Por meio dessa anotação, o leitor fica informado a respeito da condição de leitura do aluno. Consequentemente, poderia pensar em alternativas educacionais para melhorá-la.

$\mathrm{Na}$ mesma direção, registrar a reação dos alunos aos conteúdos estudados agrega sentido ao relato, possibilitando ao leitor inferir as dificuldades dos aprendizes que estão assistindo às aulas de Língua Portuguesa.

Os alunos perguntam à professora o que significa a palavra "Galeão" porque os mesmos não acharam-na no dicionário e a professora responde se tratar de um Aeroporto do Rio de Janeiro. 
Lendo o relato, podemos perceber uma dúvida entre substantivos próprios e comuns, ou mesmo, a ignorância de que não é possível encontrar os primeiros em dicionários escolares. A inserção da voz dos protagonistas da aula, portanto, permite conhecer o andamento daquele evento de maneira mais precisa.

\section{Como o estagiário constrói referências temporais}

Fornecer referências temporais claras, de maneira a instruir o leitor permitindo sua orientação com relação à sequência de eventos relatados, consiste em significativa dificuldade encontrada nos relatórios. Normalmente, cabe a quem relata fornecer adequadamente informações temporais de forma a não deixar ao leitor a tarefa de inferi-las.

Acompanhei 40 horas de observação em aula de Língua Portuguesa dispostas em oito aulas acompanhando a professora.

Fazendo-se inferências, pode-se parafrasear o que o aluno tentou construir da seguinte maneira: durante as 40 horas de observação, acompanhei a professora de Língua Portuguesa, observando, a cada vez, blocos de oito aulas. Note-se que o estudante não explicou, por ter assistido oito aulas de cada vez, foi 5 vezes à escola. Essa é uma inferência mais distante do que o texto permite por meio de marcas explícitas. Persiste aqui o problema da adequação vocabular muito semelhante ao que estava presente em Encontram-se descrito neste relatório as observações [...]. No exemplo em análise, o aluno escreve "Acompanhei 40 horas de observação em aula", sendo que the foi solicitado e o que fez foi observar 40 aulas. Para manter a escolha do verbo acompanhar a frase que estaria mais em conformidade com o que foi feito seria "Acompanhei 40 aulas nas quais fiz as observações exigidas".

Outro obstáculo a ser superado é, também, conseguir indicar o tempo dos fatos observados no texto, informando ao leitor o momento em que atividades didáticas ocorreram. A indicação do tempo com precisão é importante para se saber de que modo os conteúdos estão conectados e como se dá a sequência com que são apresentados.

No começo da observação, a professora retomava aspectos dos conhecimentos da língua portuguesa [...]. 
Os alunos na segunda aula se mostraram com muitas opiniões e chegou a haver alguns debates sobre possíveis conclusões das histórias. Foram duas aulas aproximadamente em cada classe sobre esse aspecto.

O aluno escolhe expressões vagas para fazer o seu relato, tanto para indicar o tempo, quanto para indicar o conteúdo. Tomemos a primeira indicação temporal do excerto: "no começo da observação". Sem as datas nas quais as aulas teriam ocorrido não é possível perceber a pertinência das retomadas feitas pela professora. A interpretação dessa retomada será diferente se o aluno iniciou seu estágio em março ou em maio. Ou ele estaria falando do início de cada aula observada?

Tomemos agora a segunda indicação temporal: "Os alunos na segunda aula...”. É necessário notar que não há informação que possibilite ao leitor saber se se trata da segunda aula observada durante o estágio ou da segunda aula observada em um dos dias em que o aluno esteve na escola.

Por fim, a terceira indicação temporal "foram duas aulas aproximadamente" nos coloca dúvidas quanto ao tempo e a quantidade de aulas. Dado que não se trata de um número muito grande. Ele poderia ser melhor indicado para não criar o efeito estranho que leva o leitor a se perguntar sobre o que seria duas aulas aproximadamente. Embora não esteja informado, talvez o aluno se refira a uma média.

Vejamos agora as indicações relativas ao conteúdo apenas para apontar quão vagas elas são: "aspectos dos conhecimentos da língua portuguesa" e "possíveis conclusões das histórias". Aúnica certeza que o leitor pode ter é que se trata de língua portuguesa. Definitivamente é muito pouco em termos de observação e registro de conteúdos a respeito do ensino de português para um aluno que já cursou quatro anos de Letras.

Com relação à atuação dos sujeitos no episódio registrado também não se pode ir muito longe em termos de informação: "a professora retomava aspectos" e "os alunos se mostravam com muitas opiniões".

\section{Conclusões}

Neste trabalho, destacamos algumas das dificuldades dos estudantes de letras ao escrever textos que expressem a constituição de um olhar profissional. Neste momento, estamos em condições de apontar 
alguns parâmetros mínimos para que a descrição de uma aula funcione como dado para um trabalho de pesquisa do licenciando.

$O$ curso de licenciatura precisa:

1. Ser uma instância capaz de despertar, no aluno, uma decisão de transcender o caráter burocrático das tarefas;

2. Despertar, no futuro professor, a consciência da necessidade de fazer um esforço para escrever bem. Caso não faça essa conquista, o observável se perde, na medida em que não chega a consistir em algo que poderia ser utilizado pelos leitores para melhorar sua compreensão dos impasses envolvidos no ensino da língua materna;

3. Capacitar o graduando para incluir, de forma clara, exemplos concretos em seu texto, tais como a transcrição do texto oral de uma aula, ou, mesmo, a reprodução de páginas de livro texto, ou a cópia de exercícios passados na aula;

4. Transmitir aos alunos os recursos linguísticos necessários para organizar, em seu texto, os fatos observados em uma linha de tempo tão clara quanto consistente; $\mathrm{e}$

5. Ensinar a indicar adequadamente a inclusão das palavras do outro. Um diário de campo no qual não fique claro de quem é a voz em cada uma de suas passagens não chega a configurar escrita autoral por parte de quem produz o texto.

Em resumo, estamos insistindo na ideia de que um curso de Letras deve dedicar-se ao ensino do conhecimento que compõem seus componentes básicos, oriundos dos estudos da linguagem, bem como dedicar-se a construir a capacidade de escrever bem, tal qual postulamos aqui. Tudo isso deve ser feito sem extrair do aluno sua condição de falante, a partir da qual ele pode se reler e se perguntar se, enquanto falante da língua materna, aceitaria seu próprio texto. 


\section{Referências}

Barzotto, V. H., Aragute, Tânia Aiko. (2008) O falante, o professor e o ensino de Língua Portuguesa In: Leitura, escrita e ensino. (p. 157-170). Ed. Maceió: Edufal, 2008, v.1.

Fairchild, Thomas Massao. (2013, abril.). Procuram-se professores histéricos: sobre o papel da escrita nas licenciaturas. Estilos da Clínica, pp. 71-88. Brasil, v. 18, n. 1. Recuperado a 21 de outubro de 2015, em: <http://www.revistas.usp.br/estic/article/ view/59461/62628>.

Ilari, Rodolfo. (1997). O papel da linguística nos cursos de letras. In: A linguística e o ensino de língua portuguesa. $4 \mathrm{a}$ ed. São Paulo: Martins Fontes.

Lüdke, Menga \& André, Marli E. D. (1986). Pesquisa em educação: abordagens qualitativas. Temas básicos de Educação e Ensino. Capítulos 3 e 5. São Paulo: EPU.

Rezende, Neide Luzia de (2010). - Relatório e Projeto na Licenciatura: a Escrita como Potencialização da Experiência. p. 1-14. Linha D'Água, n. 23.

Riolfi, Claudia. (2015). A língua espraiada. Campinas, SP: Mercado de Letras. 
